\title{
Product grinding influence on the drying process of dispersed titanium dioxide paste
}

\author{
Victor Marchevskii, Yaroslav Grobovenko
}

\author{
National Technical University of Ukraine "Igor Sikorsky Kyiv Polytechnic Institute"
}

Keywords:
Kinetics
Grinding
Dispersant
Coolant
Drying
Paste

Article history:

Received 2.02.2018

Received in revised form 11.06.2018

Accepted

29.06.2018

\section{Corresponding author:}

Yaroslav

Grobovenko

E-mail:

ygrobovenko@

gmail.com

\section{DOI:}

$10.24263 / 2310-$

1008-2018-6-1-10

\section{Abstract}

Introduction. The research purpose is to determine the effect of the degree of product grinding on the processes of drying titanium dioxide paste and the drying of finely divided particles of titanium dioxide to a low residual moisture content of $0.3 \%$.

Materials and methods. The processes of drying and post drying of fine disperse titanium dioxide paste in vortex fluxes of the heat carrier with the use of continuous grinding of the initial product were carried out in a conical dryer of the vortex type, which includes a special device for shredding the product - dispersant, feeder-dispenser and separation zone.

Results and discussion. The initial moisture content of titanium dioxide was $50-55 \%$. The processes of drying and post drying the paste of titanium dioxide in the vortex flow of the heat-carrier during the application of the original design of the drying apparatus with a knife dispersant and a zone of drying of the material occurred to a low residual moisture content of $0,3 \%$. In this case, the temperature of the coolant at the inlet to the drying chamber was $120{ }^{\circ} \mathrm{C}$, and the volume flow i.e. 50 $\mathrm{m}^{3}$ /hour. During the process, the values of the temperature and humidity of the coolant were automatically measured at the inlet and outlet of the drying chamber and samples of dispersed particles were taken from the grinding zone. Experimentally established dependences for calculating the degree of grinding of $\mathrm{z}$ agglomerates of titanium dioxide paste and the value of the drying rate coefficient $K_{w}$ for titanium dioxide, which is $0,17-$ $2,5 \mathrm{~m} / \mathrm{s}$ was obtained. In addition, the kinetics of the drying process completely described the drying curve, namely the initial moisture content of the paste was $U_{0}=1,17 \mathrm{~kg}_{\mathrm{w}} / \mathrm{kg}_{\text {a.d.p. }}$, $U_{\text {Icr }}=0,23 \mathrm{~kg}_{\mathrm{w}} / \mathrm{kg}_{\text {a.d.p. }}$, equilibrium moisture content i.e. $U_{2}=$ $0,003 \mathrm{~kg}_{\mathrm{w}} / \mathrm{kg}_{\text {a.d.p. }}$ In the first period, the paste was dried at $37^{\circ} \mathrm{C}$ of wet thermometer. The optimum temperature conditions of the coolant for drying the titanium dioxide paste, which are 90-120 ${ }^{\circ} \mathrm{C}$ at the entrance to the drying chamber and $65-90{ }^{\circ} \mathrm{C}$ at the outlet was obtained.

The result of calculating the mathematical model is the degree of grinding that is $10-15$ conventional units.

Conclusions. The kinetics and methods of intensification of the processes of grinding, drying and drying of agglomerates of titanium dioxide paste were investigated and the parameters necessary for designing industrial drying machines were established. 


\section{Introduction}

Over the last decade, the world market has seen a sharp increase in demand for titanium dioxide pigment $\mathrm{TiO}_{2}[1-2]$. Due to its properties, titanium dioxide is used in the production of a wide range of goods for different purposes. At the present time quite a few scientific data on the kinetics of drying process of fine paste of titanium dioxide and main parameters of drying. Also, the effect of the degree of grinding of $\mathrm{TiO}_{2}$ agglomerates on the intensity of the process of drying and drying of the product to a low residual moisture content of $0,3 \%$ remains insufficiently studied.

The process of drying paste on titanium dioxide is the most energy-intensive and limiting process in $\mathrm{TiO}_{2}$ production technology [3], which requires a reduction in the cost of heat energy for drying the paste, increasing the drying rate and improving the quality and ensuring a low residual moisture of the finished product [4]. Therefore, the study of the process of drying paste of titanium dioxide and the development of new high-efficient and energysaving equipment for obtaining a $\mathrm{TiO}_{2}$ product with high given mechanical and consumer properties is an urgent task.

The purpose of experimental studies is to determine the effect of milling agglomerates of a $\mathrm{TiO}_{2}$ paste on the processes of drying and drying the titanium dioxide paste in the vortex fluxes of the heat carrier by increasing the contact surface of the product with the coolant and the agglomeration of the agglomerates of the paste by dry powdered titanium dioxide particles.

\section{Select the type of dispersant}

In the technology of $\mathrm{TiO}_{2}$ pigment production, the process of grinding (dispersing) agglomerates of paste is one of the expensive and energy-intensive processes. The cost of production of titanium dioxide is inversely proportional to the size of the fine particle size of the pigment $\mathrm{TiO}_{2}$ [5], which according to the requirements of state standards should be not more than 15 microns [6]. In this regard, the effective shredding of the titanium dioxide pigment is the most important operation in the production process. Necessary optical properties of fine particles, and in particular e.g. the ability to disperse light (dispersing ability) e.g. the greater the finer the crushed particles of the dispersed phase. The optimum size of the particle size lies in submicron ranges.

In the drying apparatuses of the boiling layer for drying the $\mathrm{TiO}_{2}$ paste, the following types of dispersants are most commonly used (Figure 1 [7-8]):

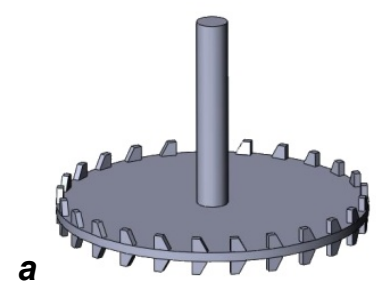

b

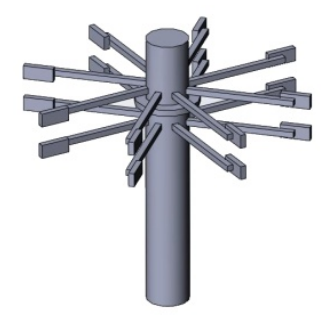

$\boldsymbol{C}$

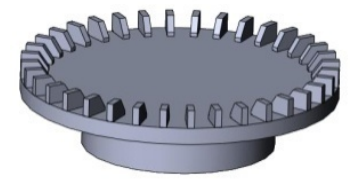

Figure 1. Types of dispersants

a - dissolver; $b$ - knife disperser; $c$ - disk dispersant 


\section{- Processes and Equipment -}

The analysis of the designs of the boiling fluid drying apparatuses with the product dispersant [6-9] shows that the most widely used knife dispersers have a number of advantages: prevents sticking the product to the surface of the camera; allows you to work at high speeds; significant speed and degree of shredding.

Therefore, one of the most important aspects for reducing production costs and cost of valuable product, as well as for guaranteeing the necessary decorative and protective properties of the titanium dioxide pigment and coatings on its basis, is the correct selection of dispersing equipment and its efficient work.

\section{Materials and methods}

\section{Experimental installation}

In order to achieve the set tasks and solve kinetic equations describing the processes of shredding, drying and drying of titanium dioxide paste, a specially designed methodology for carrying out the experiment was used.

Investigation of the processes of grinding, drying and drying of finely divided paste of titanium dioxide in vortex flow of heat carrier was carried out on a pilot drying plant. The composition of the drying unit includes (Figure 2) a drying apparatus of a vortex type equipped with a dispersant for grinding agglomerates of a paste of $\mathrm{TiO}_{2}$ [Patent of Ukraine No. 108688 of the IPC F26B 17/10 (2006.01)]. Also, the authors of the article developed a method for drying paste-like products, on which the design of a pilot drying apparatus [Patent of Ukraine No. 107089 of the IPC F26B 17/10 (2006.01)].

\section{Measuring complex}

The pressure drop in the dispersion zone and the drying zone was continuously measured by two differential pressure sensors $\mathrm{D}_{2}$ and $D_{3}$. The drive power $\mathrm{P}$ (Figure 2) of the dispersant was measured by a measuring complex of type K50 №1654, coolant flow rate i.e. difamonometer $D_{1}$, the temperature and humidity of the vortex fluxes of the coolant and particles of titanium dioxide by the computerized system when applying moisture and temperature sensors MLX90614 (W/T) with a frequency of 63 measurements per second (63 $\mathrm{Hz}$ ) connected to the computer through the controller Arduino Pro Mini. Diagram of placement of devices and data transmitters, difemometers and main elements is shown in Figure 2 .

\section{Materials}

To carry out experimental studies of the processes of grinding and drying the titanium dioxide paste, a thyrotrophic fine titanium dioxide titanium dioxide $\mathrm{TiO}_{2}$ with an initial moisture content of $\mathrm{w}=55 \%$ and a density of $\rho=2173 \mathrm{~kg} / \mathrm{m}^{3}[10]$ was used which reduced viscosity and increased fluidity under mechanical influence. Thixotropy paste is a very important indicator of the product, due to which it is possible to feed this paste of $\mathrm{TiO}_{2}$ into a drying chamber at an initial drying rate of $80 \%$ using a screw or lobed feeder [11-12], which will not clog. 


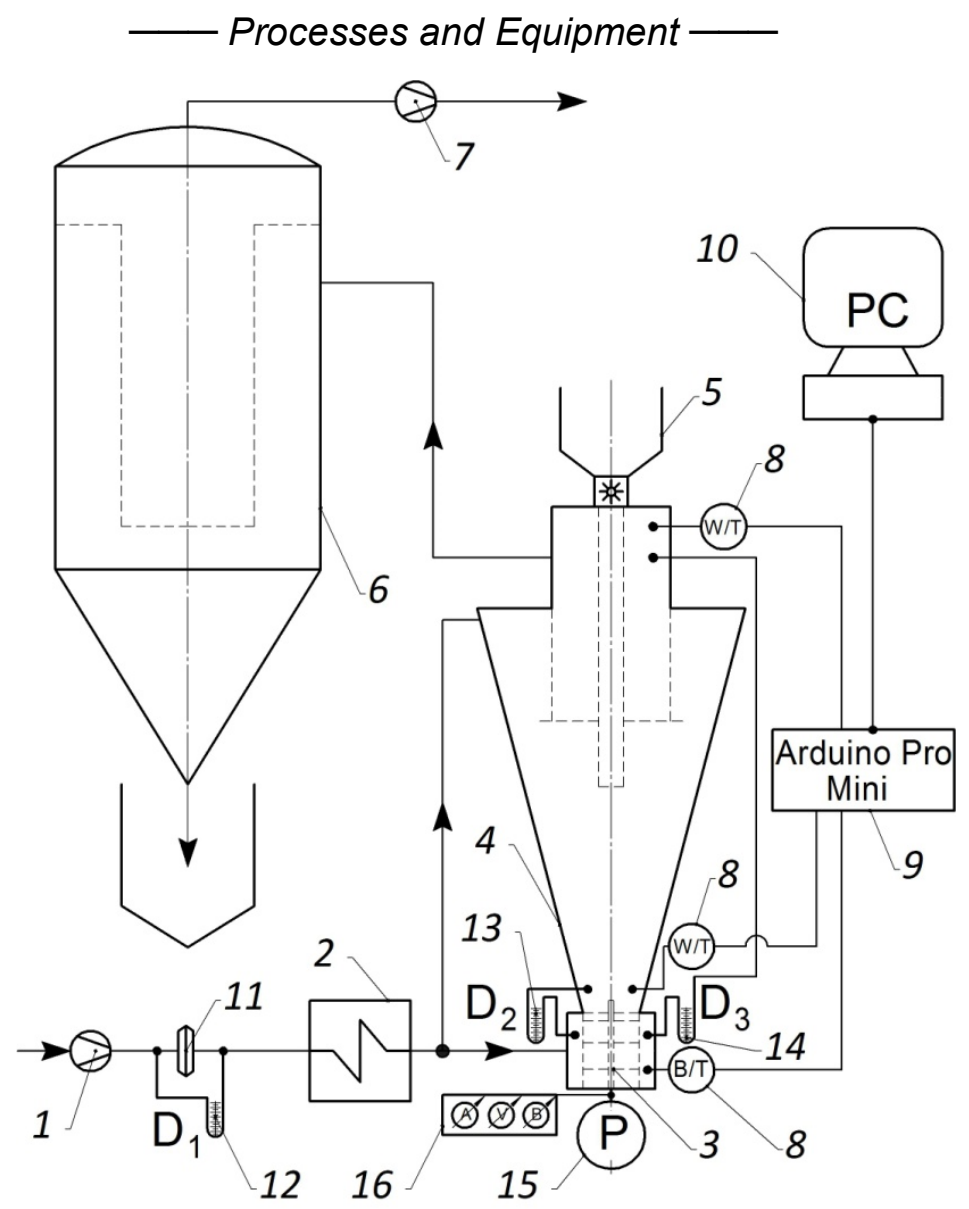

Figure 2. Scheme of a computerized system for measuring the power of a dispersant, fans, temperature and humidity in an experimental drying plant:

1, 7 - booster and exhaust fans; 2 - heater; 3 -dispersant; 4 -drying chamber; 5 - feeder-dispenser; 6 - sleeve filter; 8 - temperature and humidity sensor MLX90614 (W/T); 9 - microcontroller Arduino

Pro Mini; 10 - computer for visualization and data storage; 11 - diaphragm;

12, 13, 14 - difemometers; 15 - Electric drive; 16 - measuring complex type K50 №1654

\section{Results and discussion}

Physical modeling of the effect of the grinding process of agglomerates of $\mathrm{TiO}_{2}$ paste on the processes of drying and drying the product in a vortex dryer

Agglomerates of the $\mathrm{TiO}_{2}$ paste enter the bottom of the drying chamber (Figure 4a) using a feeder feeder on a knife disperser (Figure $4 \mathrm{~b}$ ) rotating at a speed of $2860 \mathrm{1} / \mathrm{m}$. The dispersant continuously shreds the agglomerates of the product and forms a new surface through which the product contacts the coolant. 


\section{- Processes and Equipment}

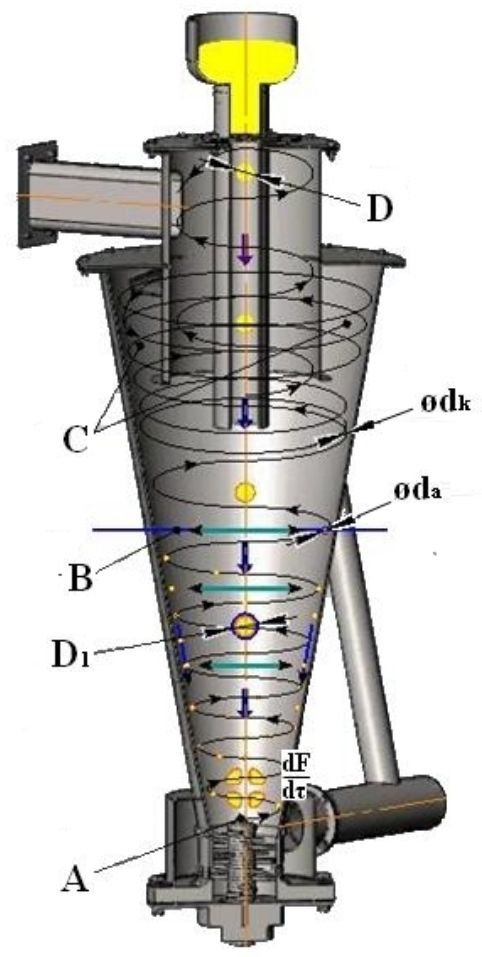

$a$

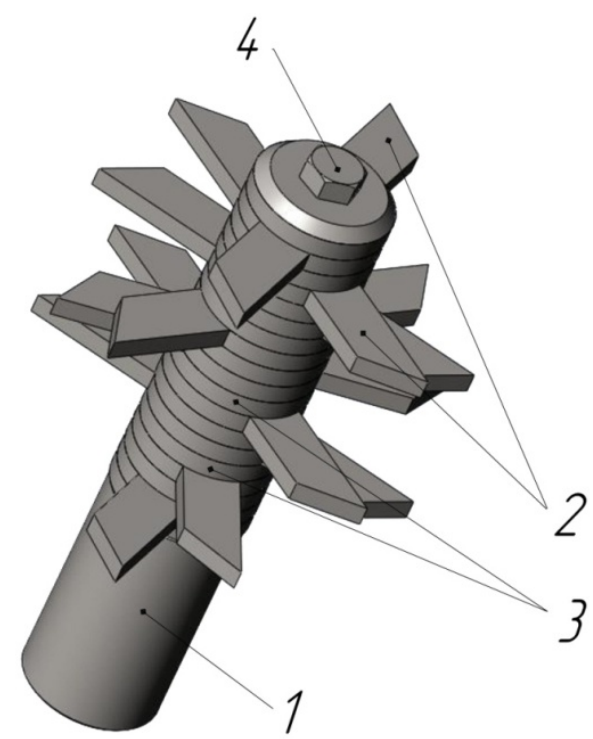

b

Figure 4. Diagram of a drying apparatus equipped with a dispersant

a - diagram of the physical model of the processes of grinding and drying paste of $\mathrm{TiO}_{2}$; $\mathrm{b}$ - knife disperser;

$\mathrm{A}$ - dispersion zone; $\mathrm{B}$ - separation zone of finely divided $\mathrm{TiO}_{2} ; \mathrm{C}$ - zone of drying powder $\mathrm{TiO}_{2}$; 1 - disperser shaft; 2 - knives; 3 - remote washers

Continuous grinding of titanium dioxide in the drying chamber of the device allows significantly increasing the drying speed of the product and reducing the energy consumption of the process.

The physical model includes shredding, drying and drying of the $\mathrm{TiO}_{2}$ paste includes:

- the supply of a thyrotrophic paste to titanium dioxide in the form of the formed separate clusters of $\mathrm{TiO}_{2}$ particles, which are interconnected by forces of surface tension in the zone of the vortex layer A;

- contact and powdering the cluster surface with the dried product;

- intensive drying of the surface moisture of the material with simultaneous continuous grinding in zone A with a knife dispersant;

- removal of small particles of product from zone A into separation zone B by a vortex flow of a coolant with reduction of the axial component of speed;

- $\quad$ separation and drying of adsorption-coupled moisture in the zone $\mathrm{C}$ of fine particles to low residual moisture content of $0.3 \%$. 


\section{- Processes and Equipment -}

Mathematical description of the processes of grinding, drying and drying of finely divided paste of titanium dioxide

Equation of the energy of the drying process [13-15]:

$$
d Q=d Q_{1}-d Q_{2}
$$

Writing the components of equation (1), we obtain:

$$
G_{\text {a.d.p. }} \cdot\left(\mathrm{c}_{\text {a.d.p. }}+c_{w} \cdot U\right) \cdot \partial t_{\text {part. }}=\alpha \cdot \frac{\partial F_{\text {part. }}}{\partial \tau} \cdot\left(t_{c .}-t_{\text {part. }}\right) \cdot \partial \tau-G_{\text {a.d.p. }} \cdot \frac{\partial U}{\partial \tau} \cdot r \cdot \partial \tau,
$$

where $d Q$ is heat flow to heat paste, $\mathrm{kJ} ; d Q_{1}$ is convective heat flow from the drying agent, $\mathrm{kJ} ; d Q_{2}$ is heat flux on the evaporation of water from the paste of titanium dioxide, $\mathrm{kJ} ; G_{\text {a.d.p. }}$. is flow of a completely dry powder of titanium dioxide, $\frac{\mathrm{kg}}{\mathrm{s}} ; \mathrm{w}$ is speed of the drying agent (air), $\frac{m}{s} ; l$ is equivalent diameter of the particle of titanium dioxide paste, $m$; $v_{c}$. is kinematic viscosity of the coolant, $\frac{\mathrm{m}^{2}}{\mathrm{~s}} ; c_{\text {a.d.p. }}$ is specific heat of a titanium dioxide powder, $\frac{\mathrm{J}}{\mathrm{kg} \cdot \mathrm{K}} ; c_{w}$ is specific heat of water, $\frac{J}{\mathrm{~kg} \cdot \mathrm{K}} ; U$ is moisture content of titanium dioxide, $\frac{\mathrm{kg} w}{\mathrm{~kg}_{\text {a.d.p }}} ; \alpha$ is mass transfer coefficient from the coolant to the particle surface, $\frac{W}{m^{2} \cdot \mathrm{K}} ; F_{\text {part. }}$. is outer surface of the particle, $m^{2} ; t_{c .}$ is temperature of coolant, ${ }^{\circ} \mathrm{C}$; $t_{\text {part }}$. is temperature of particles, ${ }^{\circ} \mathrm{C}$; $\frac{d U}{d \tau}$ is drying speed, $\frac{1}{\mathrm{~s}} ; r$ is specific heat of steam generation, $\frac{\mathrm{J}}{\mathrm{kg}} ; d \tau$ is drying time, $\mathrm{s}$.

The drying rate in the first period is limited by the amount of heat flowing from the coolant [9], and in the second period, the rate of desorption of adsorption-bound moisture. The grinding process does not limit the drying process.

On the basis of the equation of thermal energy (2), the basic equation of mass deducing [15-18] and the law of grinding [1], the mathematical description of the drying process can be represented by the following system of equations:

$$
\left\{\begin{array}{c}
\frac{\partial t_{\text {part. }}}{\partial \tau}=\alpha \cdot \frac{\partial F_{\text {part. }}}{\partial \tau} \cdot \frac{t_{c .}-t_{\text {part. }}}{G_{\text {a.d.p. }}\left(\mathrm{c}_{\text {a.d.p. }}+c_{w} \cdot U\right)}-\frac{\frac{\partial U}{\partial \tau} \cdot r}{\mathrm{c}_{\text {a.d.p. }}+c_{w} \cdot U} \\
\frac{\partial U}{\partial \tau}=\beta \cdot \frac{\partial F_{\text {part. }}}{\partial \tau} \cdot \frac{P_{s}(1-\varphi)}{P_{\text {atm. }}}-D \cdot \sum F_{\text {part. }} \cdot \frac{\partial C}{\partial R} \\
\frac{\partial F_{\text {part. }}}{\partial \tau}=k Z
\end{array}\right.
$$

where $\beta$ is mass transfer coefficient from the coolant to the particle surface, $\frac{m}{\mathrm{~s}}$;

$P_{S}$ is saturated vapor pressure, $\mathrm{Pa} ; \varphi$ is relative humidity of the coolant, $\%$;

$D$ is coefficient of molecular diffusion, $\mathrm{m} / \mathrm{s} ; k$ is grinding factor; $\mathrm{z}$ is degree of grinding; $\partial \mathrm{C}$ is the driving force of the drying process.

Initial conditions for a given system of equations (3):

$$
\begin{gathered}
\left.u\right|_{\tau=0}=u_{0}, u_{2}=u_{1 c r,} \tau_{0}=0, t_{0}=t_{1}, d_{0}=1 \mathrm{~mm}, \\
\alpha=\frac{N u \cdot \lambda_{c .}}{D} \quad[1], \\
N u=0,021 \cdot \operatorname{Re}^{0,8} \cdot \operatorname{Pr}^{0,43} \cdot\left(\frac{P r}{P r_{\text {wall }}}\right)^{0,25} \cdot \varepsilon \quad[19-20] .
\end{gathered}
$$


The dependence $\frac{\partial F_{\text {part. }} \text {. }}{\partial \tau}$ describes the process of dispersing the agglomerates of the $\mathrm{TiO}_{2}$ paste, taking into account the speed of rotation, the length of the cutting edges and the shape of the disperser knives.

\section{Experimental studies of kinetics of $\mathrm{TiO}_{2}$ drying}

Dependence of moisture content of paste on dioxide $U, \frac{k g_{\text {a.d.p. }}}{k g_{w}}$ from drying time $\tau, s$ at volume flows of the coolant $50 \mathrm{~m}^{3} / \mathrm{h}$ and initial temperatures of the coolant $90-120^{\circ} \mathrm{C}$, and the initial humidity of the paste $\mathrm{TiO}_{2} 54 \%$ is presented as a graphical dependence on figure 5 .

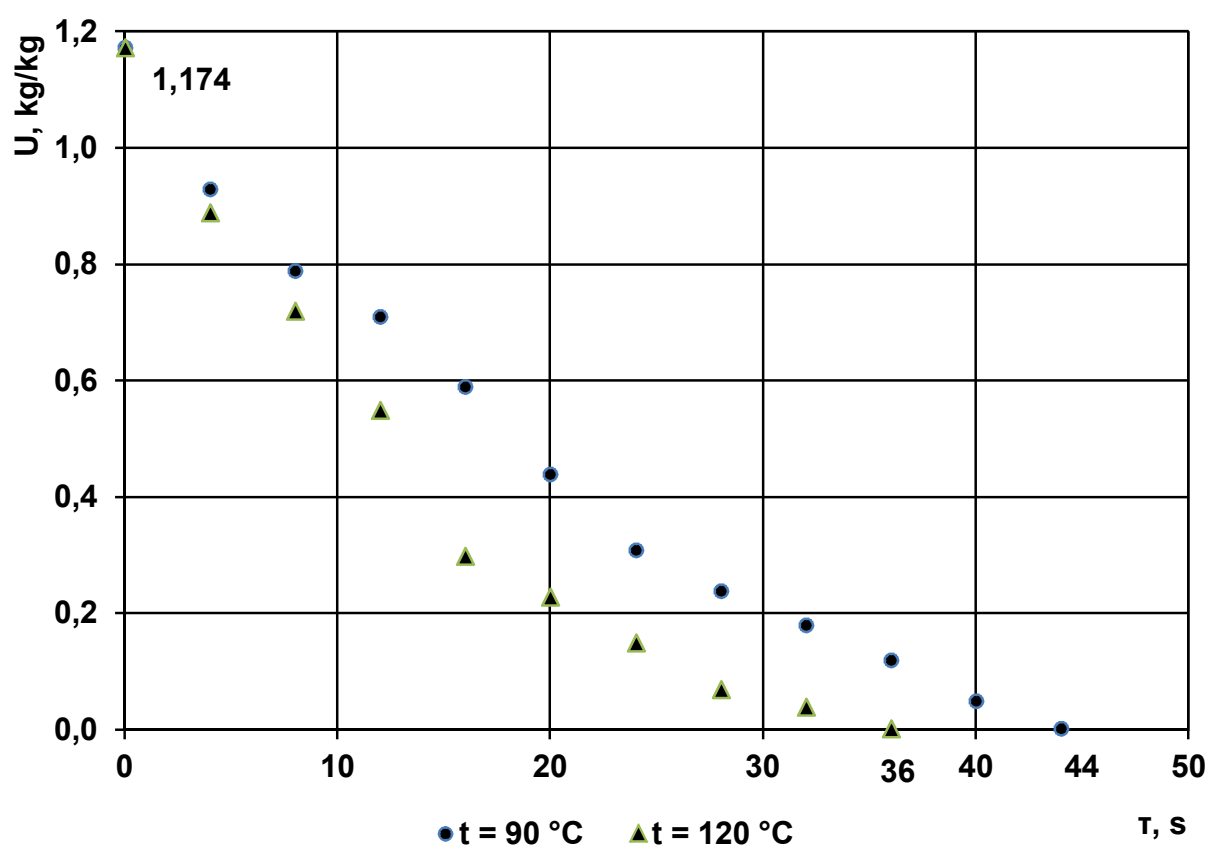

Figure 5. The dependence of the moisture content $\mathrm{U}$ of the paste $\mathrm{TiO}_{2}$ on drying time $\tau$

Figure 5 shows that the same amount of paste of titanium dioxide at an initial temperature of the coolant temperature of $120^{\circ} \mathrm{C}$ acquires equilibrium moisture content 36 seconds after the start of drying, and at $90{ }^{\circ} \mathrm{C}$ i.e. after 44 seconds. The graphs clearly show the first and second periods of drying, and the value $U_{1 c r}=0,22 \frac{k g_{a . d . p} \text {. }}{k g_{w}}$.

The thermal curves describing the experimental dependence of the temperature of the product on drying time are presented in Figure 6. 


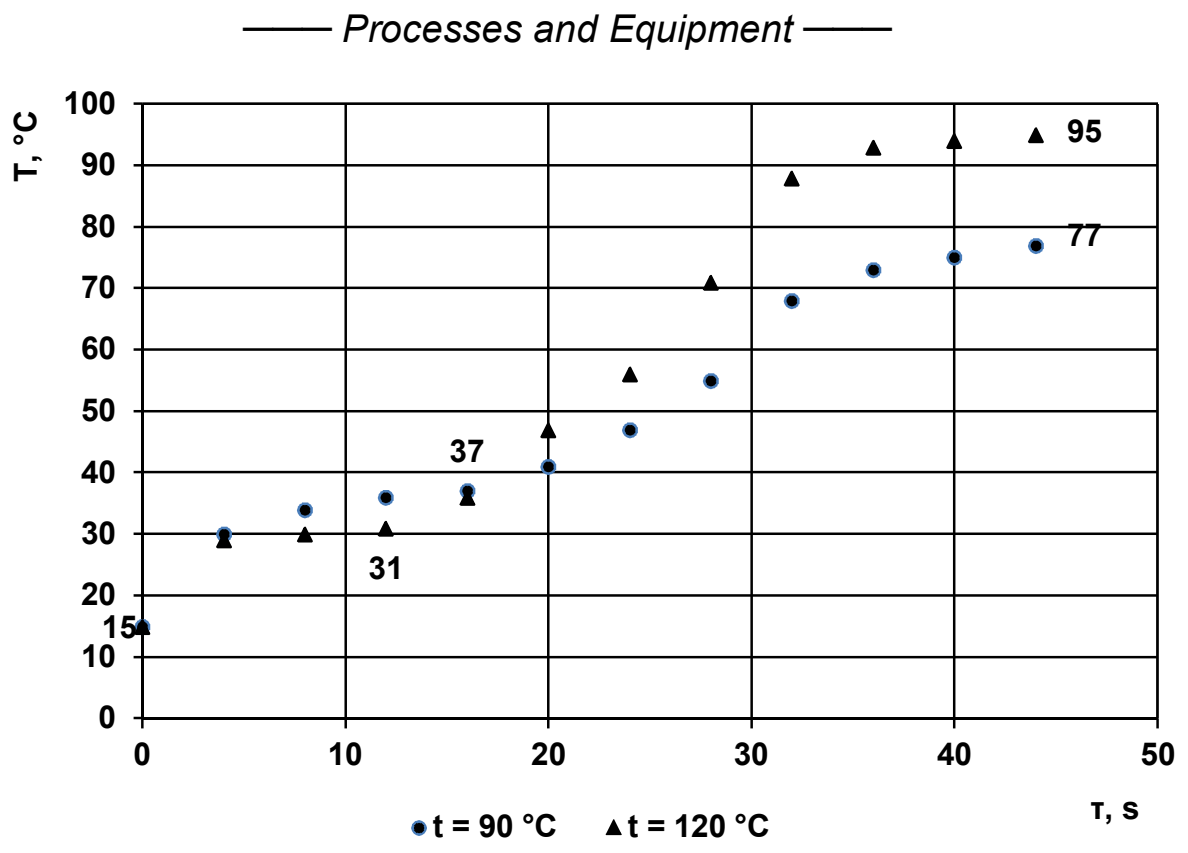

Figure 6. Dependence of temperature t on drying time $\tau$

Figure 6 shows that the temperature of the wet thermometer of the product is $31{ }^{\circ} \mathrm{C}$ and $37^{\circ} \mathrm{C}$ at an initial temperature of the coolant $90^{\circ} \mathrm{C}$ and $120^{\circ} \mathrm{C}$, respectively. From the graphs a constant temperature (temperature of the wet thermometer) is observed, which corresponds to the area of the first drying period, when the drying rate is constant.

\section{Experimental studies of the process of grinding agglomerates of paste}

The grinding process was investigated on a knife disperser (Figure 7). The dependence of the current strength on the time of dispersion is depicted in Figure 7.

The data of current strength was obtained by video recording of ammeter displays, and the time of dispersion was measured by a stopwatch. For grinding, dried in an electric oven at $\mathrm{t}=105^{\circ} \mathrm{C}$, titanium dioxide was used, since the hardness of the dry product would be much greater than the hardness of the wet paste of $\mathrm{TiO}_{2}$. Three experiments were carried out for samples of dried product $0.3 \mathrm{~kg}, 0.6 \mathrm{~kg}$ and $1 \mathrm{~kg}$. The force of the idle speed of the knife disperser was $3.5 \mathrm{~A}$.

As can be seen from Figure 7, the maximum jump in current on the dispersant drive reached $5.32 \mathrm{~A}$ when loaded with $1 \mathrm{~kg}$ of product. The grinding fine particles of the product were deposited with a coolant in the unit filter bag. 


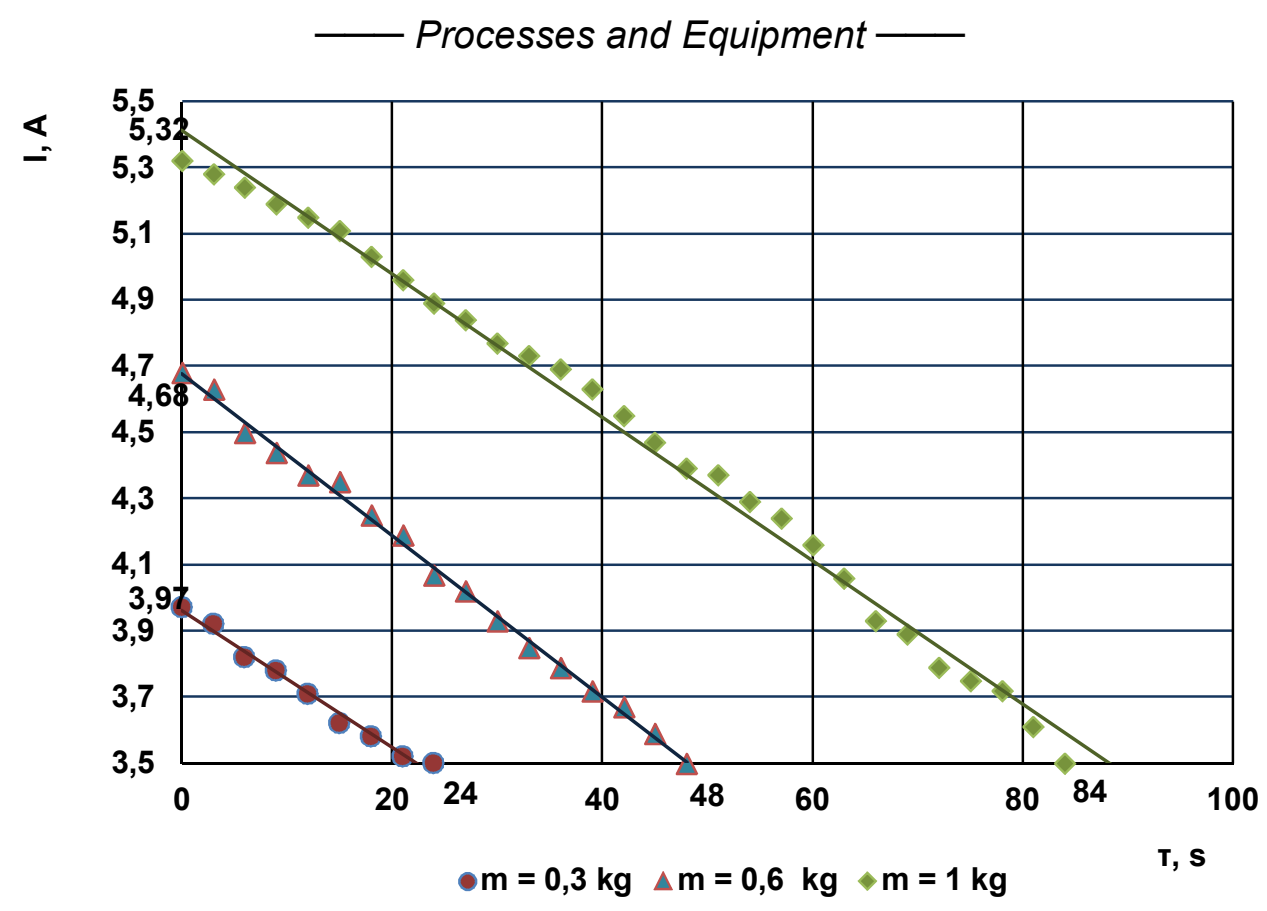

Figure 7. The dependence of the current I of the dispersant on the time of shredding $\tau$

\section{Conclusions}

It was found that the grinding process of agglomerates of $\mathrm{TiO}_{2}$ paste significantly intensifies the process of drying and drying the titanium dioxide product, which in turn increases the drying rate $\frac{\partial U}{\partial \tau}$ by continuously increasing the value $\frac{\partial F_{\text {part }} \text {. }}{\partial \tau}$.

It was established that the process of grinding agglomerates of paste of $\mathrm{TiO}_{2}$ significantly intensifies the process of drying and drying the product of titanium dioxide, namely

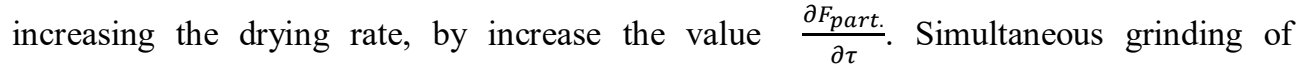
agglomerates of a product helps to reduce energy costs for further grinding of the product after the drying stage. The initial coolant temperature can be increased to $300^{\circ} \mathrm{C}$, and volume flow reduced to $30 \frac{\mathrm{m}^{3}}{\text { hour }}$. The resulting design of the dryer provides a combination of grinding, drying and drying of fine titanium dioxide paste.

The result of this work is to find ways to increase the drying rate of fine titanium dioxide paste and obtain $\mathrm{TiO} 2$ product with high specified mechanical and consumer properties.

\section{References}

1. (2014), Podbor dispergiruyushchego oborudovaniya dlya proizvodstva pigmentirovannyh lakokrasochny materialov, available at: https://www.himtekyar.ru/useful//km_technology/1669/. 


\section{- Processes and Equipment}

2. Marcus R., Leung L., Klinzing G., Rizk F. (1990), Pneumatic Conveying of Solids: A Theoretical and Practical Approach, 1st Ed, Powder Technology Series, Great Britain.

3. Pecora A., Goldstein L., Lombardi G., Pagliuso J. (1994), New particulate solids pneumatic feeding device with mass flowrate control, Powder Technology, Great Britain.

4. Pugsley T., Milne B., Berruti F. (1996), An innovative non-mechanical solids feeder for high solids mass fluxes in circulating fluidized beds, Powder Technology Journal, 2, pp. 123131.

5. Ferreira M., Freire, J. (1992), Fluid dynamics characterization of a pneumatic bed with a spouted bed type solid feeding system, The Canadian Journal of Chemical Engineering, 7, pp. 905-909.

6. Littman H., Morgan M., Paccione J., Jovanovic S., Grbavic Z. (1993), Modeling and measurement of the effective drag coefficient in decelerating and non-accelerating turbulent gas-solids dilute phase flow of large particles in a vertical transport pipe, Powder Technology Journal, 5, pp. 267-283.

7. Grobovenko Y., Marchevskii V. (2018), Kinetics of drying the titanium dioxide paste in the vortex dryer, Ukrainian Food Journal, 7(2), pp. 311-323.

8. Costa I., Ferreira M., Freire, J. (2004), Analysis of regime transitions and flow instabilities in vertical conveying if coarse particles using different solids feeding systems, The Canadian Journal of Chemical Engineering, 3, pp. 48-59.

9. Markowski A. (1992), Drying Characteristics in a Jet spouted Bed Dryer, Can. J. Chem. Eng., 5, pp. 156-163.

10. Barret N., Fane A. (1990), Drying Liquid Materials in a Spouted Bed, New York Hemisphere Publ, 8, pp. 278-286.

11. Jong J., Hoffmann A., Finkers H. (1999), Properly Determine Powder Flowability to Maximize Plant Output, Chem. Eng. Prog., 4, pp. 135-142.

12. Grobovenko Y., Marchevskii V. (2017), Modeliuvannia protsesu sushinnia dribnodyspersnykh chastynok $\mathrm{TiO}_{2}$ v pototsi sushylnoho ahentu, Visnyk Natsionalnoho tekhnichnoho universytetu Ukrainy "KPI", Khimichna inzheneriia ekolohiia ta resursozberezhennia, 1, pp. 78-81.

13. Grobovenko Y., Marchevskii V. (2018), Aerodynamika vykhrovykh potokiv sushylnoho ahentu u sushylnii kameri. Visnyk Zhytomyrskoho derzhavnoho tekhnolohichnoho universytetu, seriia "Tekhnichni nauky”, (1), pp. 22-25.

14. Grobovenko Y., Marchevskii V. (2016), Protses sushinnia pasty dioksydu tytanu u vykhrovomu sushylnomu aparati, Naukovyi zhurnal "Smart and young", 11-12, pp. 55-58.

15. Dmitriev V. (2013), Konvektivnaya sushka polidispersnykh materialov v apparatakh zakruchennogo vzveshennogo sloya, Vestnik Tambovskogo gosudarstvennogo tekhnicheskogo universiteta, 3, pp. 602-606.

16. Adamiec J. (2002), Drying of waste sludges in a fluidized bed dryer with a mixer, Drying Technology, 20, p. 839.

17. Bait R., Pawar S., Banerjee A., Mujumdar A., Thorat B. (2011), Mechanically agitated fluidized bed drying of cohesive particles at low air velocity, Drying Technology, 29, p. 808.

18. Puspasari I., Talib M., Daud W., Tasirin S. (2012), Drying kinetics of palm oil frond particles in an agitated fluidized bed dryer, Drying Technology, 30, p. 619.

19. Chongdian S., Wu J., Wang Y., Zhang Y., Shang X. (2015), Drying of low rank coals: A review of fluidized bed technologies, Drying Technology, 33, p. 277.

20. Kim J., Han G. (2006), Effect of agitation on fluidization characteristics of fine particles in a fluidized bed, Powder Technology, 166, p. 113. 